\title{
Kawasaki disease: a comprehensive review
}

Kamleshun Ramphul ${ }^{1}$, Stephanie Gonzalez Mejias ${ }^{2}$

${ }^{1}$ Department of Pediatrics, Shanghai Xin Hua Hospital affiliated to the Shanghai Jiao Tong University, School of Medicine, Shanghai, China

2Department of Pediatrics, Robert Reid Cabral Children's Hospital affiliated to the University Iberoamericana UNIBE, School of Medicine, Santo Domingo, Dominican Republic

Submitted: 5 February 2018

Accepted: 11 February 2018

Arch Med Sci Atheroscler Dis 2018; 3: e41-e45

DOI: https://doi.org/10.5114/amsad.2018.74522

Copyright $\odot 2018$ Termedia \& Banach

\author{
Corresponding author: \\ Kamleshun Ramphul \\ Department of Pediatrics \\ Shanghai Xin Hua Hospital \\ affiliated to the Shanghai \\ Jiao Tong University \\ School of Medicine \\ 1665 Kongjiang Road \\ Shanghai 200092, China \\ Phone: +23058283027 \\ E-mail: adramphul@hotmail. \\ com
}

\begin{abstract}
Kawasaki disease is an acute systemic vasculitis that was first reported in 1961. Over the last 5 decades multiple papers have been published to further understand this disease. The diagnosis of Kawasaki disease is made based on the clinical findings. Atypical Kawasaki disease includes patients who do not meet all the criteria for diagnosis. The main complication of Kawasaki disease is coronary aneurysm, and the treatment is intravenous immunoglobulin and aspirin. A second dose of immunoglobulin is given if the patient does not improve, and several other treatment options have been proposed over the last few years as second and third line options.
\end{abstract}

Key words: Kawasaki disease, coronary aneurysm, aspirin.

\section{Introduction}

Kawasaki disease (KD) is characterized as an acute systemic vascular disease that affects mostly medium sized and small vessels [1]. It is generally self-limited and the highest incidence occurs in children under five years of age. Multiple theories have been proposed for the pathophysiology of the condition but the etiology of KD remains poorly understood. Proper diagnosis based on clinical findings, proper investigations and follow-ups are important to treat and prevent associated complications of the disease.

\section{History of Kawasaki disease}

In January 1961, Dr. Tomisaku Kawasaki encountered his first case of Kawasaki disease [2]. A 4-year-old male patient presented with high fever for 2 weeks, bilateral conjunctival hyperemia, fissured, dried, reddish and bleeding lips, strawberry tongue, and diffuse erythema of the oral cavity and mucous membrane. The patient also had initial left then subsequent right cervical lymphadenopathy. Red palms and soles as well as polymorphous erythema were present all over his body. It was followed by membranous desquamation of the hands and feet over the next 2 weeks.

When the case was presented at the pediatric department meeting of the hospital, the differential diagnosis of atypical scarlet fever and milder forms of Steven-Johnson syndrome was suggested, but no proper diagnosis was confirmed on discharge. Dr. Kawasaki then encountered a second case a year later in 1962 in a 2-year-old male patient presenting 
with similar symptoms, and by October that year he had come across another 5 cases. He reported these 7 cases in a paper at the Chiba Prefecture Pediatric meeting; however there was no positive feedback at that time.

Over the next 5 years following the initial case, Dr. Kawasaki observed 50 cases with similar presentations, following which he published a paper entitled 'Acute febrile musculocutaneous lymph node syndrome: clinical observation of 50 cases' in the Japanese Journal of Allergy in 1967. His paper received proper recognition 35 years later from the western side of the world when Dr. Jane Burns from the University of California San Diego presented the paper in English in the Pediatric Infectious Diseases Journal. From 1970, Dr Kawasaki managed to obtain proper funding to study the disease and the initial diagnostic guidelines were established. The committee also came across cases resulting in death and the autopsy showed presence of coronary aneurysm. Coronary angiography was performed to confirm the presence of coronary aneurysm in some of the patients and the introduction of better 2D echocardiography in 1976 allowed better progress to be made in the field [3].

\section{Epidemiology}

Kawasaki disease has a universal distribution and has been found in children of different ethnicities worldwide. The prevalence of KD is higher in Asian countries such as Japan, where the annual incidence rate rose from 239.6 per 100000 children in 2010 [4] to 264 per 100,000 children recently [5]. It has been reported that the incidence of KD had peaks in January and June/ July and was lowest in October. The incidence of the disease was also at its peak in the US during winter as well as early spring [6]. There is also a higher risk among Korean and Taiwanese children, where 134 and 66, respectively, out of 100000 children under 5 years of age have the disease $[7,8]$. The prevalence is significantly lower in non-Asian countries; 8.39 per 100000 children in England [9], and 9.34 per 100000 children under 5 years in Australia [10].

\section{Etiology and pathophysiology}

Multiple theories have been hypothesized for the etiology of KD. It is currently believed that there is a genetic predisposition to the development of KD and the interaction of an unknown infective cause can also predispose to KD [11].

Current evidence strongly suggests that genetic factors have a more important role in the occurrence of KD. Polymorphisms of the IgG receptor can increase the susceptibility of children to KD and increase the risk of developing coronary artery aneurysm. The higher prevalence of KD among Asian countries such as Japan, Korea and Taiwan compared to non-Asian countries also suggests a strong genetic susceptibility based on ethnicity. Japanese American children in Hawaii had a higher incidence rate of 210 per 100000 compared to 13 per 100000 in Caucasian American children living in the same area in Hawaii [12]. Various genome-wide association studies in KD have also been reported [13-17].

An infective cause was also suggested for the incidence of KD. The major epidemics of KD in Japan have shown origination in specific areas and peak incidence in specific months [18]. The acute onset of the disease mimics viral and bacterial infection patterns. In 2013 Jaggi et al. suggested that there could be a relationship between an infection with adenovirus and the onset of KD. Other studies have suggested that a virus could have been inhaled and later engulfed by tissue macrophages leading to activation of the innate immune response. Further activation of the adaptive immune responses can lead to antigen specific $T$ lymphocytes and plasma cell activation. The presence of the infection in coronary tissue leads to secretion of multiple growth factors such as vascular endothelial growth factors, tumor necrosis factor- $\alpha$ (TNF- $\alpha$ ), and metalloproteinase 9, leading to destruction of the intima, and fragmentation of the internal and external elastic lamina of the coronary artery. This results in the development of a coronary artery aneurysm [19] Furthermore, it has also been suggested that KD antibodies can identify intra-cytoplasmic inclusion bodies in tissues. Other studies have also reported several inclusion bodies corresponding to aggregates of viral RNA and proteins that are yet to be identified [20].

\section{Diagnosis}

The diagnosis of KD relies mostly on clinical signs and symptoms. The criteria in the US require the presence of fever for at least 5 days along with four of five other clinical features listed in Table I.

An algorithm was created by the American Heart Association (AHA) in 2004 to help identify patients at risk [21]. The statement suggests the use of supportive laboratory testing and echocardiography to help detect patients who are at risk and do not meet all the criteria for diagnosis. These were termed "incomplete" KD or "atypical" KD patients, but they are still at risk for developing KD. An Australian study suggested that this occurs in up to $9.6 \%$ of cases of KD [10]. Suggested laboratory testing included markers of inflammation, presence of anemia, leukocytosis, thrombocytosis, hypoalbuminemia, elevated liver enzymes and possible sterile pyuria. An echocardiogram can 
also help rule out the presence of any early coronary artery abnormalities or involvement.

The multiple differential diagnosis to rule out KD includes drug hypersensitivity, Stevens-Johnson syndrome, staphylococcal scalded skin syndrome, juvenile idiopathic arthritis, toxic shock syndrome, viral infection, and streptococcal scarlet fever [21].

\section{Treatment}

Kawasaki disease is treated with intravenous immunoglobulin (IVIG) and high dose aspirin, although the use of aspirin in the management has been controversial in some studies [22-24]. A metaanalysis showed that the use of corticosteroids with IVIG as initial treatment has a better effect on reducing the risk of coronary artery abnormalities compared to the use of IVIG only [25]. It is highly recommended to start the treatment immediately if the patient meets the clinical criteria for KD.

The IVIG can prevent the development of coronary artery aneurysms. The use and dose of IVIG have been supported by multiple randomized controlled trials [26-28]. It has a dose-dependent effect; a single dose of $2 \mathrm{~g} / \mathrm{kg}$ is administered within 10 days of illness or later if the patient has signs of inflammation, persistent fever or aneurysm on echocardiography. It can lower the risk of giant aneurysm to $1 \%$ and coronary artery aneurysms from $25 \%$ to less than $5 \%[21,22]$. The IVIG can influence the $T$ cell activity and reduce the synthesis of antibodies and cytokines causing the symptoms of KD [21, 29-32].

Aspirin is believed to modify the inflammatory state present in KD and prevent the risk of thrombosis. Some studies have however questioned the impact of aspirin use in KD to prevent the development of coronary aneurysm [21, 22, $24,33]$. The AHA recommends administration of a high dose of aspirin of 80 to $100 \mathrm{mg}$ /day divided into 4 doses until the patient is afebrile for 48 to $72 \mathrm{~h}$. The dose is then reduced to 3 to $5 \mathrm{mg} /$ $\mathrm{kg} /$ day as a single dose for 6 to 8 weeks after the onset of the disease. It is also recommended to continue the use of aspirin if there are any persisting coronary abnormalities [21, 24]. Children on long courses of aspirin are recommended to receive the influenza vaccine to prevent the risk of Reye syndrome.

If the patient does not respond to the initial therapy, a second infusion of IVIG at $2 \mathrm{~g} / \mathrm{kg}$ is administered. Kobayashi et al. conducted a retrospective study in 2013 and found that the use of corticosteroids along with IVIG for patients with refractory KD showed better improvement and also lowered the risk of coronary aneurysms [34]. The AHA has also suggested the use of TNF- $\alpha$ antagonists in patients who do not re-
Table I. Diagnostic criteria for Kawasaki disease. Four of these five plus a fever of more than 5 days confirms the diagnosis of Kawasaki disease

\begin{tabular}{|c|c|}
\hline Conjunctiva & $\begin{array}{l}\text { - Bilateral } \\
\text { - Painless } \\
\text { - Nonexudative }\end{array}$ \\
\hline Lymphadenopathy & $\begin{array}{l}\text { - Cervical, usually more than } \\
1.5 \mathrm{~cm} \\
\text { - More commonly unilateral }\end{array}$ \\
\hline Skin rash & - Commonly maculopapular \\
\hline Extremity changes & $\begin{array}{l}\text { - Acute phase: erythema and } \\
\text { induration of hands } \\
\text { and/or feet } \\
\text { - Subacute phase: periungual } \\
\text { desquamation may follow }\end{array}$ \\
\hline Mucosal changes & $\begin{array}{l}\text { - Red, cracked lips } \\
\text { - Glossitis with hyperplastic } \\
\text { fungiform papillae seen as } \\
\text { strawberry tongue } \\
\text { - Diffuse erythema of the oral } \\
\text { mucosa or oropharynx }\end{array}$ \\
\hline
\end{tabular}

spond to IVIG. The use of infliximab had faster resolution compared to IVIG retreatment in some studies, while other studies have shown that the use of infliximab helped decrease the duration of fever but did not provide an improvement in treatment over IVIG and aspirin when used alone [35]. Patients with refractory KD and mild to moderate aneurysm can be treated with aspirin alone or along with antiplatelet agents. Larger aneurysms can be treated with heparin and warfarin as required [21].

Other possible treatment options that have been proposed include the use of cyclosporine $A$ and methotrexate. Cyclosporine $A$ is a calcineurin inhibitor that targets the $\mathrm{Ca}^{2+}$ /NFAT signaling pathway. It leads to a decrease in inflammatory response $[13,36]$. It has been used as a third line of treatment in some cases of KD in Japan $[37,38]$. Methotrexate can lead to the accumulation of polyglutamate metabolites in the cells [39]. Since the mechanism of action and its role in KD are not fully understood, the AHA does not have any recommendations for its use in KD [40].

\section{Prognostic factors}

Some prognostic factors for the development of coronary aneurysm in KD patients identified in some studies that involved Japanese children are male sex, C-reactive protein (CRP) > $200 \mathrm{mg} / \mathrm{dl}$, age less than 12 months old or more than 8 years old, albumin $<35 \mathrm{~g} /$, platelet count $<35 \times 10^{4}$ / $\mathrm{mm}^{3}$, delay of initiation of IVIG, lower dose of IVIG and recurrent $\mathrm{KD}[41,42]$. One study suggested a score system to identify patients at risk of IVIG resistance as shown in Table II. A combined score 
Table II. Predicting the risk of intravenous immunoglobulin (IVIG) resistance in Kawasaki disease

\begin{tabular}{|lcc|}
\hline Parameter & Cut-off value & Point \\
\hline Sodium & $\leq 133 \mathrm{mmol} / \mathrm{l}$ & 2 \\
\hline Aspartate aminotransferase & $\geq 100 \mathrm{IU} / \mathrm{l}$ & 2 \\
\hline C-reactive protein & $\geq 10 \mathrm{mg} / \mathrm{dl}$ & 1 \\
\hline Neutrophils & $\geq 80 \%$ & 2 \\
\hline Platelet count & $\leq 30.0 \times 10^{4} / \mathrm{mm}^{3}$ & 1 \\
\hline Duration of illness before initial treatment & $\leq 4$ days & 2 \\
\hline Age & $\leq 12$ months old & 1 \\
\hline
\end{tabular}

of 0 to 3 predicted a low risk while a score of more than 4 suggested a higher risk of having resistance to IVIG therapy $[43,44]$.

\section{Long-term follow-up}

The AHA recommends a baseline echocardiography examination during the acute phase of the illness. Repeated echocardiography is also recommended at week 2 and weeks $6-8$ after the illness [21]. If there is evidence of higher risk factors or poor recovery, more frequent imaging is recommended.

The AHA also advised that patients who are at low risk and with no detectable coronary abnormalities should be followed for at least 10 to 20 years after being diagnosed with KD, even in the absence of any abnormalities. For moderate-risk patients if there is regression of the aneurysm at weeks 6 to 8, they can be treated as lowrisk patients. Regular cardiac assessments every 3 to 5 years are recommended. High-risk patients have a higher likelihood of having progression to coronary artery stenosis. The long-term use of anti-platelet therapy and warfarin or heparin is strongly recommended. $\beta$-Blockers can be added to decrease the myocardial oxygen demand. A thorough cardiac examination, electrocardiogram and echocardiogram should be performed at least twice a year. It is also advised to do a yearly stress test and perfusion study. Patients should be advised to limit physical activities based on their conditions and their risks of bleeding. More invasive tests such as angiography can be performed as needed per case [45].

\section{Conclusions}

While Kawasaki disease remains a poorly understood condition, it can be managed with proper treatment and follow-up. A rapid diagnosis and treatment can immensely help improve the prognosis and lower the associated complications of KD. Recent advances in the treatment and detection of KD such as the discovery of NT-proBNP as a biomarker for early detection of the disease show a promising future to combat KD. More expert consensus along with multiple published clinical experiences will continue to help in guiding the proper management of KD.

\section{Conflict of interest}

The authors declare no conflict of interest.

\section{References}

1. Ozen S, Ruperto N, Dillon MJ, et al. EULAR/PReS endorsed consensus criteria for the classification of childhood vasculitides. Ann Rheum Dis 2006; 65: 936-41.

2. Kawasaki T. Acute febrile mucocutaneous syndrome with lymphoid involvement with specific desquamation of the fingers and toes in children. Arerugi [Allergy] 1967; 16: 178-222.

3. Kawasaki T, Naoe S. History of Kawasaki disease. Clin Exp Nephrol 2014; 18: 301-4.

4. Nakamura Y, Yashiro M, Uehara R, et al. Epidemiologic features of Kawasaki disease in Japan: results of the 2009-2010 nationwide survey. J Epidemiol 2012; 22: 216-21.

5. Harnden A, Tulloh R, Burgner D. Kawasaki disease. BMJ 2014; 349: g5336.

6. Burns JC, Cayan DR, Tong G, et al. Seasonality and temporal clustering of Kawasaki syndrome. Epidemiology 2005; 16: 220-5.

7. Kim GB, Han JW, Park YW, et al. Epidemiologic features of Kawasaki disease in South Korea: data from nationwide survey, 2009-2011. Pediatr Infect Dis J 2014; 33: 24-7.

8. Lue HC, Chen LR, Lin MT, et al. Epidemiological features of Kawasaki disease in Taiwan, 1976-2007: results of five nationwide questionnaire hospital surveys. Pediatr Neonatol 2014; 55: 92-6.

9. Harnden A, Mayon-White R, Perera R, Yeates D, Goldacre M, Burgner D. Kawasaki disease in England: ethnicity, deprivation, and respiratory pathogens. Pediatr Infect Dis J 2009; 28: 21-4.

10. Saundankar J, Yim D, Itotoh B, et al. The epidemiology and clinical features of Kawasaki disease in Australia. Pediatrics 2014; 133: e1009-14.

11. Burns JC, Capparelli EV, Brown JA, Newburger JW, Glode MP. Intravenous gamma-globulin treatment and retreatment in Kawasaki disease. US/Canadian Kawasaki Syndrome Study Group. Pediatr Infect Dis J 1998; 17: $1144-8$. 
12. Uehara R, Belay ED. Epidemiology of Kawasaki disease in Asia, Europe, and the United States. J Epidemiol 2012; 22: 79-85.

13. Onouchi Y, Ozaki K, Buns JC, et al. Common variants in CASP3 confer susceptibility to Kawasaki disease. Human Mol Genet 2010; 19: 2898-906.

14. Burgner D, Davila S, Breunis WB, et al. A genome-wide association study identifies novel and functionally related susceptibility loci for Kawasaki disease. PLoS Genetics 2009; 5: e1000319.

15. Kim JJ, Hong YM, Sohn S, et al. A genome-wide association analysis reveals $1 p 31$ and 2 p13.3 as susceptibility loci for Kawasaki disease. Human Genetics 2011; 129: 487-95.

16. Tsai FJ, Lee YC, Chang JS, et al. Identification of novel susceptibility loci for Kawasaki disease in a Han Chinese population by a genome-wide association study. PloS One 2011; 6: e16853.

17. Khor CC, Davila S, Breunis WB, et al. Genome-wide association study identifies FCGR2A as a susceptibility locus for Kawasaki disease. Nature Genetics 2011; 43: 1241-6.

18. Yanagawa H, Nakamura Y, Ojima T, Yashiro M, Tanihara S, Oki I. Changes in epidemic patterns of Kawasaki disease in Japan. Pediatr Infect Dis J 1999; 18: 64-6.

19. Rowley AH, Baker SC, Orenstein JM, Shulman ST. Searching for the cause of Kawasaki disease: cytoplasmic inclusion bodies provide new insight. Nature Rev Microbiol 2008; 6: 394-401.

20. Rowley AH. Kawasaki disease: novel insights into etiology and genetic susceptibility. Ann Review Med 2011; 62: 69-77.

21. Newburger JW, Takahashi M, Gerber MA, et al. Diagnosis, treatment, and long-term management of Kawasaki disease: a statement for health professionals from the Committee on Rheumatic Fever, Endocarditis, and Kawasaki Disease, Council on Cardiovascular Disease in the Young, American Heart Association. Pediatrics 2004; 114: 1708-33.

22. Terai M, Shulman ST. Prevalence of coronary artery abnormalities in Kawasaki disease is highly dependent on gamma globulin dose but independent of salicylate dose. J Pediatr 1997; 131: 888-93.

23. Lee G, Lee SE, Hong YM, Sohn S. Is high-dose aspirin necessary in the acute phase of Kawasaki disease? Korean Circulation J 2013; 43: 182-6.

24. Baumer JH, Love SJ, Gupta A, Haines LC, Maconochie I, Dua JS. Salicylate for the treatment of Kawasaki disease in children. Cochrane Database Syst Rev 2006; 4: Cd004175.

25. Chen S, Dong Y, Yin Y, Krucoff MW. Intravenous immunoglobulin plus corticosteroid to prevent coronary artery abnormalities in Kawasaki disease: a meta-analysis. Heart 2013; 99: 76-82.

26. McCrindle BW, Rowley AH, Newburger JW, et al. Diagnosis, treatment, and long-term management of Kawasaki disease: a scientific statement for health professionals from the American Heart Association. Circulation 2017; 135: e927-99.

27. Newburger JW, Takahashi M, Beiser AS, et al. A single intravenous infusion of gamma globulin as compared with four infusions in the treatment of acute Kawasaki syndrome. N Engl J Med 1991; 324: 1633-9.

28. Newburger JW, Takahashi M, Burns JC, et al. The treatment of Kawasaki syndrome with intravenous gamma globulin. N Engl J Med 1986; 315: 341-7.
29. Sato YZ, Molkara DP, Daniels LB, et al. Cardiovascular biomarkers in acute Kawasaki disease. Int J Cardiol 2013; 164: 58-63.

30. Burns JC, Franco A. The immunomodulatory effects of intravenous immunoglobulin therapy in Kawasaki disease. Expert Rev Clin Immunol 2015; 11: 819-25.

31. Suzuki H, Uemura S, Tone $S$, et al. Effects of immunoglobulin and gamma-interferon on the production of tumour necrosis factor-alpha and interleukin-1 beta by peripheral blood monocytes in the acute phase of Kawasaki disease. Eur J Pediatr 1996; 155: 291-6.

32. Arend WP, Leung DY. IgG induction of IL-1 receptor antagonist production by human monocytes. Immunol Rev 1994; 139: 71-8.

33. Checkley W, Robinson CL, Baumann LM, et al. 25-hydroxy vitamin D levels are associated with childhood asthma in a population-based study in Peru. Clin Exp Allergy 2015; 45: 273-82.

34. Kobayashi T, Kobayashi T, Morikawa A, et al. Efficacy of intravenous immunoglobulin combined with prednisolone following resistance to initial intravenous immunoglobulin treatment of acute Kawasaki disease. J Pediatr 2013; 163: 521-6.

35. Tremoulet AH, Jain S, Jaggi P, et al. Infliximab for intensification of primary therapy for Kawasaki disease: a phase 3 randomised, double-blind, placebo-controlled trial. Lancet 2014; 383: 1731-8.

36. Dietz SM, van Stijn D, Burgner D, et al. Dissecting Kawasaki disease: a state-of-the-art review. Eur J Pediatr 2017; 176: 995-1009.

37. Suzuki H, Terai M, Hamada H, et al. Cyclosporin A treatment for Kawasaki disease refractory to initial and additional intravenous immunoglobulin. Pediatr Infect Dis J 2011; 30: 871-6.

38. Hamada H, Suzuki H, Abe J, et al. Inflammatory cytokine profiles during cyclosporin treatment for immunoglobulin-resistant Kawasaki disease. Cytokine 2012; 60: 681-5.

39. van der Heijden JW, Assaraf YG, Gerards AH, et al. Methotrexate analogues display enhanced inhibition of TNF-alpha production in whole blood from RA patients. Scand J Rheumatol 2014; 43: 9-16.

40. Lee TJ, Kim KH, Chun JK, Kim DS. Low-dose methotrexate therapy for intravenous immunoglobulin-resistant Kawasaki disease. Yonsei Med J 2008; 49: 714-8.

41. Harada K. Intravenous gamma-globulin treatment in Kawasaki disease. Acta Paediatr Japonica 1991; 33: 805-10.

42. Giannouli G, Tzoumaka-Bakoula C, Kopsidas I, Papadogeorgou P, Chrousos GP, Michos A. Epidemiology and risk factors for coronary artery abnormalities in children with complete and incomplete Kawasaki disease during a 10-year period. Pediatr Cardiol 2013; 34: 1476-81.

43. Kobayashi T, Inoue Y, Takeuchi K, et al. Prediction of intravenous immunoglobulin unresponsiveness in patients with Kawasaki disease. Circulation 2006; 113: 2606-12.

44. Seki M, Kobayashi T, Kobayashi T, et al. External validation of a risk score to predict intravenous immunoglobulin resistance in patients with Kawasaki disease. Pediatr Infect Dis J 2011; 30: 145-7.

45. Manlhiot C, Niedra E, McCrindle BW. Long-term management of Kawasaki disease: implications for the adult patient. Pediatr Neonatol 2013; 54: 12-21. 